\title{
Implementation of the Quality Management System (ISO 9001: 2015) in the Bodywork Industry
}

\author{
Franklin W. Salazar ${ }^{1}$, Franklin G. Tigre ${ }^{1}$, Edith Elena Tubón-Núñez ${ }^{1}$, Sandra Carrillo ${ }^{1}$, Jorge Buele ${ }^{1 *}$ \\ ${ }^{1}$ Universidad Técnica de Ambato, Facultad de Tecnologias de la Información, Telecomunicaciones e Industrial, ECUADOR
}

*Corresponding Author: jl.buele@uta.edu.ec

Citation: Salazar, F. W., Tigre, F. G., Tubón-Núñez, E. E, Carrillo, S. and Buele, J. (2019). Implementation of the Quality Management System (ISO 9001: 2015) in the Bodywork Industry. Journal of Information Systems Engineering \& Management, 4(2), em0091. https://doi.org/10.29333/jisem/5890

Published: August 22, 2019

\begin{abstract}
This paper discusses the management of the quality system in a coachwork company based on the ISO 9001 standard, version 2015 and it aims directing and controlling the productive processes to ensure compliance with the operation parameters and to achieve the expected effects. The development of this action research comprises: (i) description of the manufacturing processes, (ii) diagnosis of the ISO 9001:2015 requirements, (iii) documentation structure of the QMS and (iv) development of the Quality Route method as an improvement for critical processes which generate non-compliant results. The proposed continuous improvement model aims to adapt the company to current market needs and meet the customers' necessities, allowing the enterprise to increase its productivity and profitability thanks to the systematic optimization and development of its processes. This encourages a specific management and generates positive changes in the organization, maintaining a vision of improvement and continuous innovation, in search of assurance of the quality of the products/services. In the application allows to compare with the initial situation made to the manufactured product, and it is found that the percentage of defects decreased from $72.0 \%$ to $36.0 \%$. The method of the Quality Route based on the Deming cycle with its stages; plan, do, check and act, implemented as a continuous improvement action in body manufacturing processes, allows solving problems from identified improvement opportunities, establishing a quality control system in the manufacturing phases of the product, through the execution of visual inspections and use of records.
\end{abstract}

Keywords: ISO standards, manufacturing industries, project management, quality metrics, standards organizations

\section{INTRODUCTION}

Worldwide, the vehicle coachwork companies think in the production as a transformation process of raw materials into aggregated value products. Over the years, the manufacturing of metallic structures for buses has evolved in correspondence with people's demands and with technology progresses, that is why, industries have had to implement a QMS under the ISO 9001:2015 standard, promoting a permanent control of the operative's processes and obtaining quality products with a high technical standard at international level.

The Quality Management System (QMS) ISO 9001, is the most adopted quality management model worldwide, having nowadays more than 1.1 million of certificates given to manufacturing and service organizations (Chen et al., 2016). Where quality management has seen an evolution in the following stages: quality control, quality assurance, total quality and finally, the emerging of business excellence models. Quality assurance stage starts when the company's direction gives importance to the implementation of the QMS ISO 9001, for meeting client's 
exigencies and considering products quality as an advantage facing the market competition (Esgarrancho et al., 2017).

The implementation of a QMS ISO 9001, improves industry's performance because it promotes a process approach and it meets the rules and client's requirements, contributing in the products manufacturing which meet parameters as comfort, security and quality (Ruamchat et al., 2017). In the coachwork industry, the adoption of QMS from the family of ISO 9001, provides a standardization of its processes, promoting the continuous improvement based on the Deming cycle, helping to face the threats of the competition in the national and international market (Schmeleva, 2017).

ISO 9001:2015 standard is the quality management model most known and certified around the world. The current version is focused on adapting to complex environments and on including new business practices. The requirements of this model are generic and applicable to any kind of enterprise regardless of its size or its activity. The application in new industrial sectors is framed in the evolution of the standard, improving the internal and external competitiveness of the business, strengthening the capacity of supplying consistent and high-quality products (Ruamchat et al., 2017). The requirements for implementing a QMS according to the methodology of the ISO, are non-rigid elements. For this reason, the QMS requires a constant upgrade for satisfying the organization and the client's needs. The current internationally approved standard has a high-level structure improving the relations between: the management systems, the concerned parties, an efficient process management, and the adoption of the risk-based approach (Valmohammadi et al., 2017).

The risk-based approach of the current version of ISO, the Failure Mode Effects Analysis (FMEA) and the Quality Route are processes of a high reach when managing the improvement actions inside any QMS. FMEA and Quality Route represent tools allowing to identify the main failures in the productive methods, avoiding reprocessing activities and bringing benefits and costs reductions to the organization (Solomon et al., 2017). The Quality Route method is intended to identify and solve problems in product manufacturing with the aim of reducing internal failures and perform a continuous improvement of the processes, it identifies the improvement opportunities and reduces the non-conformities of higher occurrence that affect the quality of the product.

Nowadays, coachwork companies search client's satisfaction and economic efficiency, known as business excellence, for this the following actions need to be taken: a continuous improvement of the processes; reduction of failure percentage in products; programing rigorous controls in manufacturing and respecting the established quality specifications (Fernández-S. et al., 2019). In Latin America there are many coachwork enterprises distributed in each country. The industries, for meeting the demand of high-quality products, started the implementation of a QMS based on the ISO 9001:2015 regulation which is a model focused on a continuous improvement and on achieving business objectives, increasing effectiveness and efficiency, improving the processes and optimizing the industry resources (Juanzon et al., 2017). In the last report made by the National Coachwork Manufacturers (CANFAC) for 41 nationally approved companies in year 2014, it was found that coachwork companies having a QMS ISO 9001:2008 represented 24\%, while 7\% was still in process of its adoption, 68\% had not implemented any QMS and 1\% was not registered in the coachwork guild (Chiarini, 2017).

There are several researches with topics related to the implementation of ISO standards for the continuous improvement of processes. In the research work of (Mihajlović, 2018), she presents a series of methods and techniques of quality process improvement in the milk industry in the republic of Serbia. With the initial hypothesis that the improvement of quality processes directly influences the competitive position of the company, it is determined that there is a dominant use of the method based on the PDCA cycle to improve the quality of internal processes. Similarly, in the work of (Velasco et al., 2018) the low level of safety within the critical processes of the manufacturing industry is evaluated in order to reduce productivity risks. This study proposes the implementation of an Information Security Management System (ISMS) in accordance with the ISO 27001 standard, applying the Deming methodology (PDCA). In addition, as presented in the investigation of (Sanz-Calcedo, 2015) the use of several standards (ISO 9001: 2015, ISO 14001: 2015, OHSAS 18001: 2007) can be merged to perform the analysis on integrated quality management, medium environment and safety in industrial projects. From a qualitative point of view, the possibility of managing integrated projects of quality, environment and safety in the industry is determined, through the integration of traditional systems associated with international standards.

With a sustainable theoretical foundation from the aforementioned research has been able to acquire the basis for the development of this proposal applied to the manufacturing industry (Franklin et al., 2019). In this paper, the current situation of an industry is analyzed to identify possible risks and the bodybuilding sector is presented as a case study. The objective is to promote the focus of the processes when developing and implementing a quality management system (QMS), in order to guarantee the correct manufacture of metal structures for buses. In addition, a systematic planning of the processes and their interactions is developed, by providing the necessary resources and that these are managed in an appropriate manner, focused on the cycle of continuous improvement Plan, Do, Check and Act (PDCA). All this based on the requirements established in ISO 9001: 2015. The results 


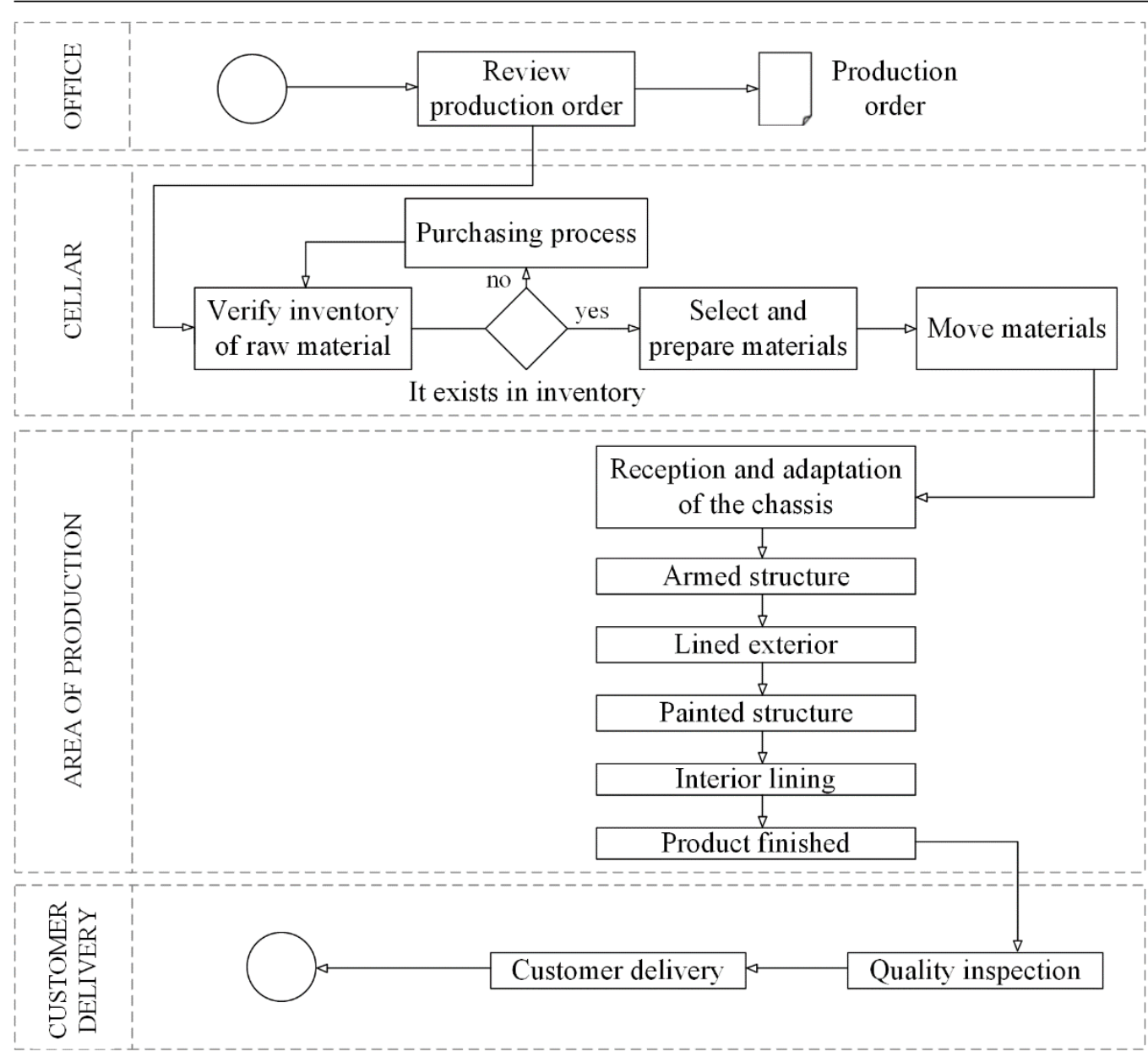

Figure 1. Flow Diagram of the manufacturing process

show that there is a reduction in critical processes and with this, it is sought to improve the integrity of the processes, for a correct administration with medium-term benefits.

This project is divided into 5 sections, including the introduction in section 1 , section 2 presents the study case. In section 3 the Deming Cycle methodology is detailed. Section 4 describes the discussion of results and its conclusions are presented in section 5.

Coachwork manufacturing has a high complexity level due to some aspects such as design, time and available workforce. Next, a description of the identified manufacturing processes is presented below.

\section{STUDY CASE}

\section{Description of Manufacturing Process for Buses Coachwork}

Coachwork manufacturing has a high complexity level due to some aspects such as design, time and available workforce. Next, a description of the identified manufacturing processes is presented below:

(i) Structure Assembly. The body structure is formed by tubes, sections, angles and metal sheets. All elements are made of steel and attached one to each other by means of weldings, rivets, screws and bolts that determine the shape of the coachwork.

(ii) Structure Lining. The structure is completely covered by coils, steel sheets and prefabricated glass fibers, installed by means of solders, screws, rivets and waterproof paste.

(iii) Paint. Design and full paint of the vehicle body according to the bus company.

(iv) Finish. Installation of many accessories inside and outside the coachwork ensuring the expected features of the body.

\section{Stages of the Manufacturing Process}

The coachwork manufacturing process has a sequence of activities which include from the initial order of manufacture until the final delivery to the client as depicted in Figure 1. 
Table 1. Development of the continuous improvement project

\begin{tabular}{|c|c|c|c|c|c|}
\hline & & Proj & ject of route of quality & & \\
\hline & Description & & Detail & & \\
\hline Process & $\begin{array}{l}\text { Identification of improvement } \\
\text { opportunities }\end{array}$ & $\begin{array}{l}\text { Prioritization of car b } \\
\text { Finished }\end{array}$ & body fabrication processes: Armed wit & struct & e, Lined, Painted, \\
\hline Objective & Pretensions to be achieved & $\begin{array}{l}\text { Reduce the number } \\
\text { manufacture }\end{array}$ & of defects in the body at the end of ea & proce & involved in the \\
\hline Scope & $\begin{array}{l}\text { Determination of } \\
\text { improvement processes }\end{array}$ & $\begin{array}{l}\text { Applies indices of de } \\
\text { dissatisfaction due to }\end{array}$ & $\begin{array}{l}\text { fects in the manufactured body, causi } \\
\text { poor product quality }\end{array}$ & repro & esses and customer \\
\hline $\begin{array}{l}\text { Definition of } \\
\text { the Problem }\end{array}$ & $\begin{array}{l}\text { Current situation of the } \\
\text { improvement processes }\end{array}$ & $\begin{array}{l}\text { Name } \\
\text { indicator }\end{array}$ & Formula & Unit & Goal \\
\hline \multirow{8}{*}{ Indicators } & \multirow{8}{*}{$\begin{array}{l}\text { Level of improvement } \\
\text { looking at manufacturing } \\
\text { processes }\end{array}$} & \multicolumn{4}{|c|}{ Armed Structure } \\
\hline & & $\begin{array}{l}\text { Defects of structure } \\
\text { reinforcement }\end{array}$ & $\begin{array}{c}\text { (Total defective welds found / \# of } \\
\text { welds to be evaluated) } * 100\end{array}$ & $\%$ & Reduce to $10 \%$ \\
\hline & & \multicolumn{4}{|c|}{$\begin{array}{ll}\text { Lining } \\
\end{array}$} \\
\hline & & $\begin{array}{l}\text { Defects of lining of } \\
\text { the structure }\end{array}$ & $\begin{array}{c}\text { (\# of lined defects / Total } \\
\text { inspection points established }) * 10\end{array}$ & $\%$ & Reduce to $10 \%$ \\
\hline & & \multicolumn{4}{|c|}{ Paint } \\
\hline & & Paint Defects & $\begin{array}{l}\text { (\# of paint defects / Total set } \\
\text { inspection points) } * 100\end{array}$ & $\%$ & Reduce to $10 \%$ \\
\hline & & \multicolumn{4}{|c|}{ Finished } \\
\hline & & Defects of finished & $\begin{array}{l}\text { (\# of finished defects / Total of } \\
\text { inspection points established) } * 100\end{array}$ & $\%$ & Reduce to $10 \%$ \\
\hline
\end{tabular}

\section{Current State of Requirements According to the ISO 9001:2015 Standard}

The diagnosis of the current situation of the company concerning the required documentation by the ISO 9001:2015 standard, was done through a checklist consisting on a question bank in correspondence with the requirements described on chapters 4 and 10 of this international standard. The data analysis was quantitative and very useful for having a clear idea of the conformity percentage according to the established requisites and was the starting point for doing the documentation structure of the QMS.

\section{Documentation Structure of QMS ISO 9001:2015}

ISO has always required a documented QMS, so the information related to the documentation must be up to date and well preserved by the organization. The documentation structure developed in this paper aims to guarantee an efficient management of the QMS.

(i) Quality Manual. The company's quality manual has the documentation of the QMS, based on the requirements of ISO 9001:2015. In this manual the quality policy and goals are described, defining the scope of the organizational management of its processes.

(ii) Procedures Manual. The procedures manual includes the description of the activities needed for executing the operations, which must be carried out in the organization according to the quality management. In addition, the responsible for the corresponding activities are identified and established.

(iii) Records. The records intend to provide evidence of the controlled activities implementation. This control can be carried out through verifications, inspections and preventive or corrective actions, in order to show the achieved results of the quality management.

\section{Quality Route Development}

Increases in coachwork demands for buses of the different modalities, lead the company to focus all its efforts on implementing projects of continuous improvement for the manufacturing processes. This brought the development of many improvement actions through the Quality Route method, which follows the PDCA cycle. This standard procedure is based on facts and data, aiming the improvement of work areas.

\section{DEMING CYCLE METHODOLOGY}

\section{Plan}

(i) Prioritize the redesign of manufacturing processes to be improved. In Table 1 are listed the body manufacturing processes to be improved and also the objective, scope and established indicators.

(ii) Determine opportunities for improvement (defects). The improvement opportunities are shown in Table 1, which lists the defects observed during product inspection. These defects obviously have the highest probability of failure and generate problems in the manufacturing processes developed in the company. 


\section{CAUSE-AND-EFFECT DIAGRAM}

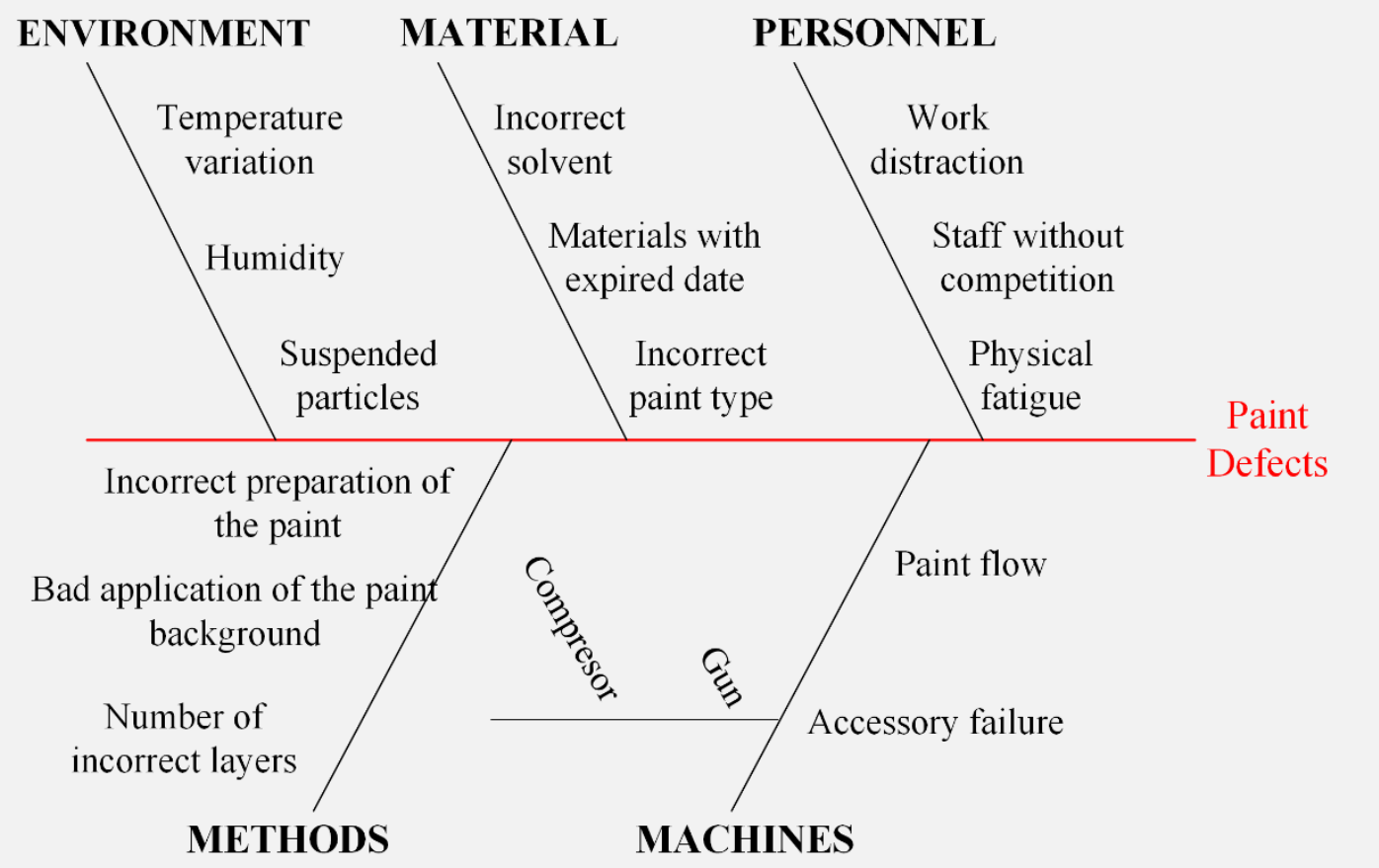

Figure 2. Ishikawa's Diagram - Paint Process

Table 2. Defects of the Structure Assembly Process

\begin{tabular}{lll}
\hline Processes & Improvement actions & Detail \\
\hline - Armed structure & -Determine the defects of greater occurrence in the processes of construction of bodies. & - Product \\
- Lined structure & -Apply inspection points of product quality, during and after each identified process to improve. & - Quality \\
- Pint & -Develop formats for the registration and analysis of data obtained from quality inspection for making & - Control \\
- Finished & decisions based on facts. & - Records \\
\hline
\end{tabular}

Table 3. Improvement Actions

\begin{tabular}{lccc}
\hline Causes & Frequency & Relative Frequency & Cumulative Relative Frequency \\
\hline Porosities & 22 & $69 \%$ & $69 \%$ \\
\hline Cracks & 8 & $25 \%$ & $94 \%$ \\
\hline Lack of penetration & 2 & $6 \%$ & $100 \%$ \\
\hline Undermining & 0 & $0 \%$ & $100 \%$ \\
\hline Excess penetration & 0 & $0 \%$ & $100 \%$ \\
\hline Total & & \multicolumn{2}{c}{32} \\
\hline
\end{tabular}

(iii) Define possible causes. For defining the possible causes of the problems generated in the manufacturing processes, an Ishikawa's or cause-effect diagram was used. As an example, a cause-effect diagram for the nonconformity in the Paint process is shown in Figure 2, showing the different defects found.

(iv) Determine improvement actions. After defining and analyzing the defects, its causes and the undesired effects on the manufacturing processes of buses bodies, improvement actions are suggested for each kind of defect found in the visual inspection of the final product, as shown in Table 2. These actions will be implemented on the manufacturing processes needing to be improved.

Do

For executing the improvement actions, the potential defects were determined and systematic controls were carried out by doing visual inspections of bodies of the "E17" model, which is the most frequently manufactured in the company, object of study.

Using the records of the QMS, information on the potential defects was collected for its further quality control analysis, obtaining the results listed below. In Table 3 and Table 4, and in Figure 3 and Figure 4, the prioritization of the defects with greater occurrence, according to the Pareto principle, are shown.

In Figure 3, the results for the Structure Assembly process are shown, proving that 69\% of defects are caused by porosities in the welding bead while 31\% corresponds to defects related with cracks and lack of penetration. These non-conformities require corrections for meeting the quality standards of the product. 


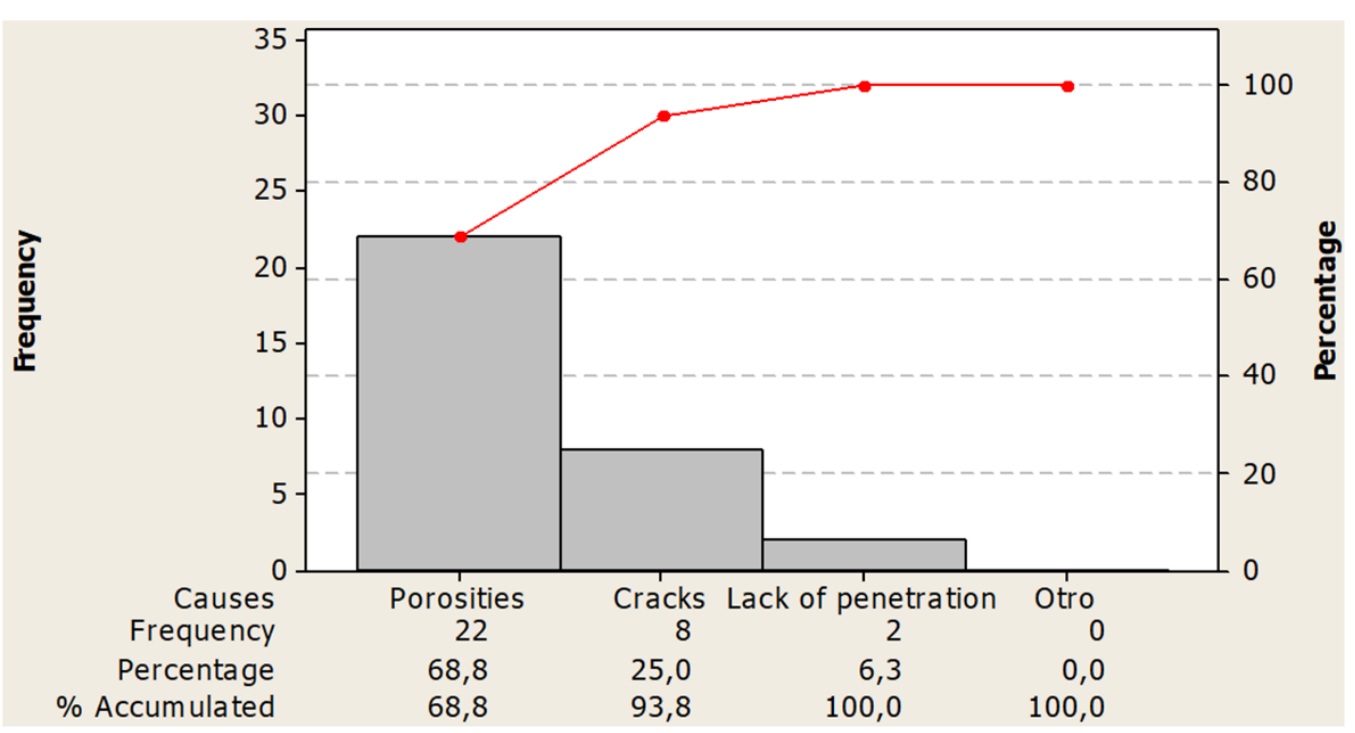

Figure 3. Pareto Diagram - Structure Assembly process

Table 4. Defects of the Structure Lining process

\begin{tabular}{lccc}
\hline Causes & Frequency & Relative Frequency & Cumulative Relative Frequency \\
\hline Wrinkled coil & 7 & $16 \%$ & $16 \%$ \\
\hline Sikaflex stains & 7 & $16 \%$ & $32 \%$ \\
\hline Badly installed coil & 6 & $14 \%$ & $45 \%$ \\
\hline Bad application of Sikaflex & 6 & $14 \%$ & $59 \%$ \\
\hline Sealant spots & 5 & $11 \%$ & $70 \%$ \\
\hline Polishing marks & 4 & $9 \%$ & $80 \%$ \\
\hline Broken glass fiber & 3 & $7 \%$ & $86 \%$ \\
\hline Fiberglass badly installed & 3 & $7 \%$ & $93 \%$ \\
\hline Bad application of sealant & 3 & $7 \%$ & $100 \%$ \\
\hline Total & & 44 & \\
\hline
\end{tabular}

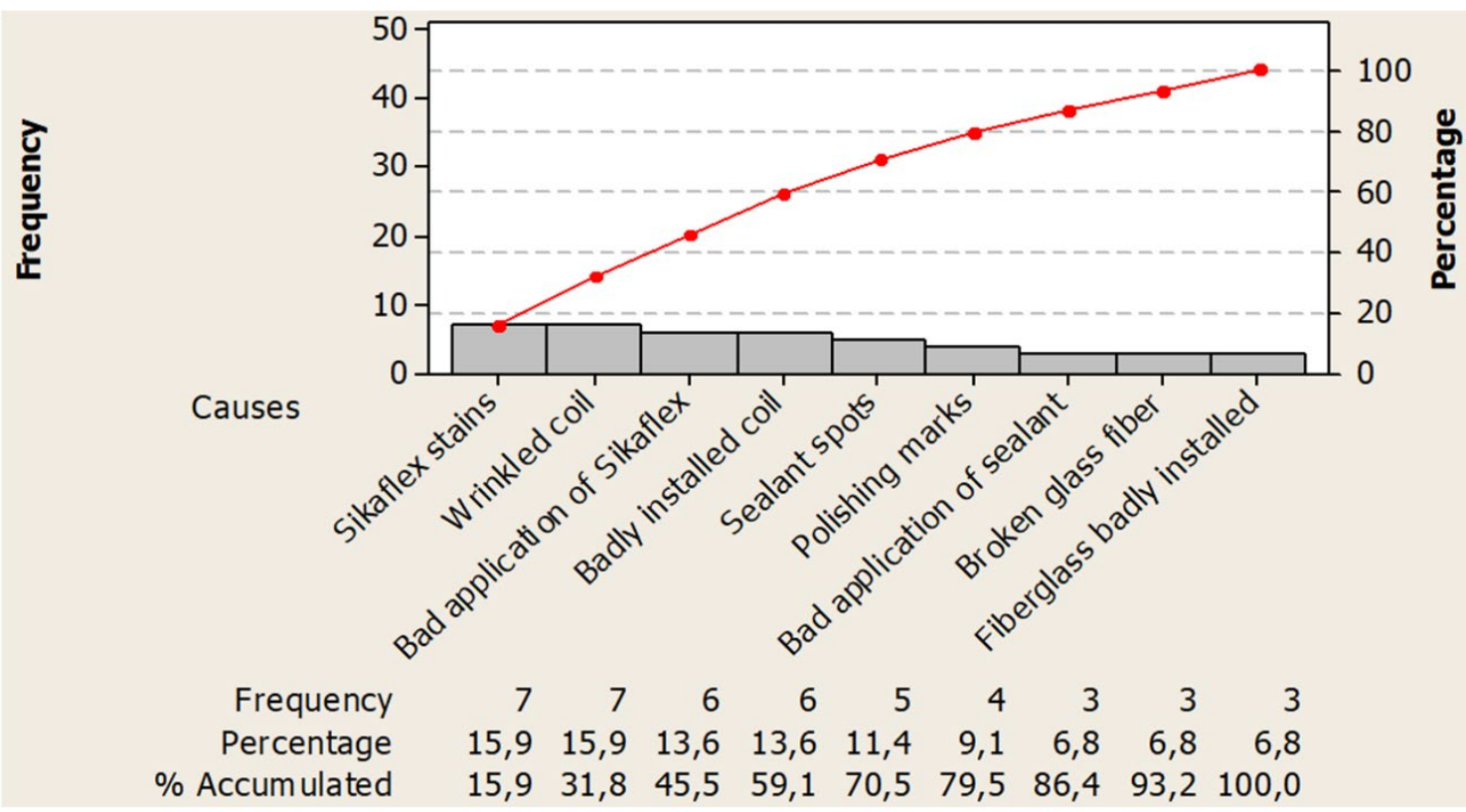

Figure 4. Pareto Diagram- Structure Lining process

Figure 4 shows the Lining process data, where it was found that $80 \%$ of defects correspond with: wrinkled coil, Sikaflex stains, badly installed coil, bad application of Sikaflex and sealant stains. The remaining 20\% corresponds to defects of: polishing marks, broken and badly installed Fiberglass, bad application of the sealant. All this failures demand to be corrected immediately. 
Table 5. Results of applying the Improvement actions

\begin{tabular}{|c|c|c|c|c|}
\hline Indicator name & Formula & Application & Unit & Goal \\
\hline \multicolumn{5}{|c|}{ Armed of the structure } \\
\hline $\begin{array}{l}\text { Defects of structure } \\
\text { reinforcement }\end{array}$ & $\begin{array}{l}\text { (Total defective welds found / \# of welds to } \\
\text { be evaluated) } * 100\end{array}$ & $(32 / 62) * 100=51.6$ & $\%$ & Reduce to $10 \%$ \\
\hline \multicolumn{5}{|c|}{ Lined structure } \\
\hline Lining defects & $\begin{array}{l}\text { (\# defects of lining / total inspection points } \\
\text { established) } * 100\end{array}$ & $(44 / 70) * 100=62.9$ & $\%$ & Reduce to $10 \%$ \\
\hline \multicolumn{5}{|c|}{ Painted } \\
\hline Paint defects & $\begin{array}{c}\text { (\# of paint defects / total inspection points } \\
\text { set) } * 100\end{array}$ & $(36 / 50) * 100=72.0$ & & Reduce to $10 \%$ \\
\hline \multicolumn{5}{|c|}{ Finished } \\
\hline Defects of finished & $\begin{array}{c}\text { (\# of finished defects / total inspection } \\
\text { points set) } * 100\end{array}$ & $(40 / 70) * 100=57.1$ & $\%$ & Reduce to $10 \%$ \\
\hline
\end{tabular}

\section{Check}

The global results obtained concerning the performance indicators established on the Quality Route project, are tools that allowed to describe the characteristics or conditions derived from the developed activities and to check as well, the evolution of the defects found in the coachwork manufacturing processes, based on the premise that "Quality of that we do cannot be improved if we don't measure our work". In Table 5 it can be observed that the Paint process has the greater percentage of defects in comparison with the rest of processes, having a value of $72.0 \%$. The Paint process is a vital stage in coachwork manufacturing along with the Finish process because the results of both are observed in detail by the client when receiving the final product.

\section{Act}

(i) Preventing recurrence of non-conformities. The next step in the Quality Route is the elimination or reduction of potential defects detected on the Paint process. For this, the coachwork painting procedure was developed and implemented, with the aim of standardizing the way activities are carried out and providing quality control parameters for the buses final paint coat.

(ii) Conclusion for the improvement plan. The application of the Quality Route method provides a guide for solving problems in the manufacturing processes of coachwork, for achieving the goals established by the Company's senior management; creating a prestigious brand in the sector and satisfy the client needs. Additionally, a methodology is established for improving the rest of the processes involved in the manufacturing of vehicle bodies.

The global results obtained concerning the performance indicators established on the Quality Route project, are tools that allowed to describe the characteristics or conditions derived from the developed activities and to check as well, the evolution of the defects found in the coachwork manufacturing processes, based on the premise that "Quality of that we do cannot be improved if we don't measure our work". In Table 5 it can be observed that the Paint process has the greater percentage of defects in comparison with the rest of processes, having a value of $72.0 \%$. The Paint process is a vital stage in coachwork manufacturing along with the Finish process because the results of both are observed in detail by the client when receiving the final product.

\section{DISCUSSION OF RESULTS}

\section{Result's Tabulation, Analysis and Interpretation of Current Status of Requirements According to ISO 9001:2015}

Table 6 shows the general results of the diagnosis made to the company regarding the required documentation described in chapters 4 through 10 of ISO 9001:2015. From a total of 103 criteria assessed on mandatory requirements of ISO $9001: 2015$, it was determined that a total of 43 criteria, which corresponds to only $42 \%$ of the sample, meets the international standard, while $58 \%$ corresponding to other 60 criteria, does not meet the established standards.

ISO 9001:2015 specifies 4 documents and 18 records for implementing and certifying the QMS. The requirements of the standard in the chapters 4,7 and 8 refer to the context of the organization, support and operation. The organization takes into consideration internal and external aspects that may affect its capacity of achieving its planned goals. In addition, necessary resources are provided for monitoring and tracking products and services in correspondence with their requirements. With respect to the operation, the organization effectively defines the criteria and processes for products and customer services. 
Table 6. Results of the ISO 9001:2015 evaluation

\begin{tabular}{|c|c|c|c|c|}
\hline \multirow[b]{2}{*}{ ISO 9001:2015 } & \multicolumn{4}{|c|}{ Qualification } \\
\hline & C: Comply & NC: Fails & NA: Does not apply & Criteria evaluated \\
\hline Context of the organization & 6 & 7 & 0 & 13 \\
\hline Leadership & 0 & 6 & 0 & 6 \\
\hline Planning & 0 & 6 & 0 & 6 \\
\hline Support for & 5 & 1 & 0 & 6 \\
\hline Operation & 32 & 13 & 0 & 45 \\
\hline Evaluating performance & 0 & 20 & 0 & 20 \\
\hline Improvement & 0 & 7 & 0 & 7 \\
\hline Total Value & 43 & 60 & 0 & 103 \\
\hline Total \% & $42 \%$ & $58 \%$ & $0 \%$ & $100 \%$ \\
\hline
\end{tabular}

Table 7. Defects on the Paint process (After improvement)

\begin{tabular}{|c|c|c|c|c|}
\hline Defects & Count & Indicator & Formula & Application \\
\hline Bad surface sanding & 6 & \multirow{10}{*}{$\begin{array}{l}\text { Defects of the } \\
\text { painting process }\end{array}$} & \multirow{10}{*}{$\begin{array}{l}\text { Number of paint defects / } \\
\text { Total inspection points } \\
\text { established } * 100\end{array}$} & \multirow{10}{*}{$(18 / 50) * 100=36,0$} \\
\hline Putty bad application & 5 & & & \\
\hline Unhooked (dripped) & 4 & & & \\
\hline Badly polished & 3 & & & \\
\hline Bubble formation & 3 & & & \\
\hline Sanding and polishing marks & 2 & & & \\
\hline Non-uniform brightness & 2 & & & \\
\hline Craters & 2 & & & \\
\hline Dirt-dust & 1 & & & \\
\hline Bad first application & 0 & & & \\
\hline
\end{tabular}

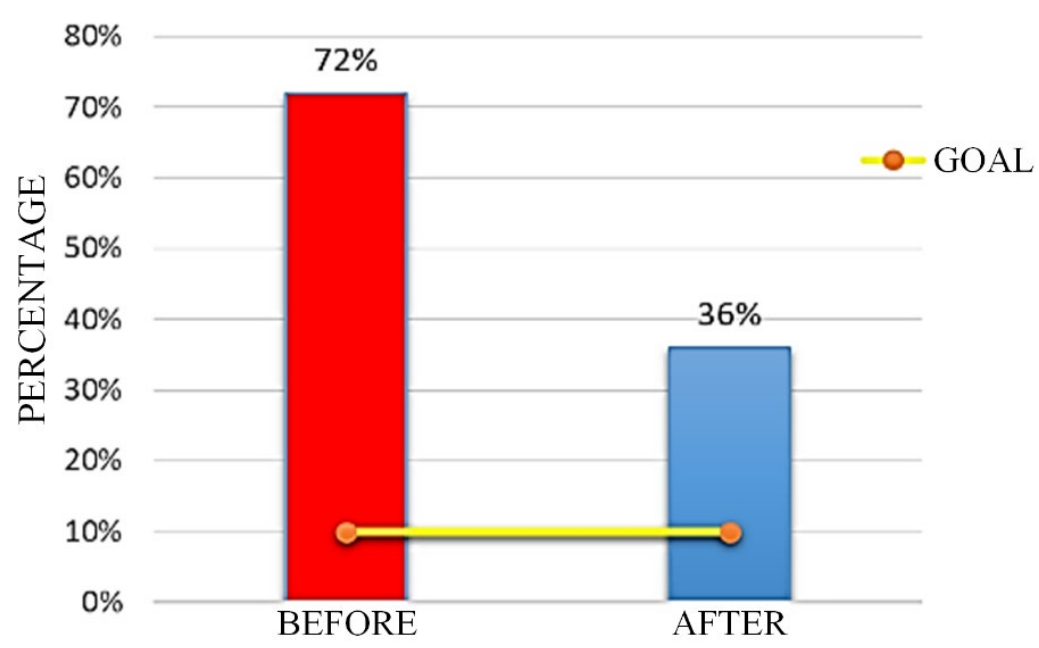

Figure 5. Defects on the Paint process (Before and after)

The coachwork company has not completely defined aspects about the commitment of the senior management personnel, showing a lack of responsibility. The inappropriate performance evaluation of productive processes affects the continuous improvement plan because of the non-conformities found without having any associated corrective actions. These requirements appear in chapters 5, 6, 9 and 10, demonstrating the greatest occurrence of non-conformities evaluated on then checklist.

\section{Analysis of Results of the Painting Process after Applying the Quality Route Method}

Table 7 shows the obtained results after implementing the quality improvement actions of the product in the Paint process, validating the effectiveness of the established action plan of continuous improvement. In Figure 5 the improvement achieved in the Paint process is shown, if we compare with the first inspection carried out to the manufactured product, the defects percentage decreased from $72.0 \%$ to $36.0 \%$. The preset goal by the company's senior management was reducing the defects index to $10 \%$ or eliminating the non-conformities permanently by applying systematically the Quality Route method as a continuous improvement action in further productions, resulting in profits for the company and satisfying the clients with quality products. The organization did not count with an improvement work plan. With this proposal, a set of control, analysis and verification procedures were implemented. Work stations are expected to reduce flaws in products and services and the credibility of the business is expected to rise. 


\section{CONCLUSIONS}

Manufacturing processes of buses' metal structures in a coachwork company were carried out by describing and surveying processes, detailing and determining the responsible actors, the target, indicator, inputs, resources and outputs on manufacturing the product. Besides, a deficient control of information by the administration was found. The diagnosis of mandatory requirements of ISO 9001:2015 showed the current status of the requirements of the international standard, referencing those chapters related to minimal requirements about the documentation managed and kept by the organization as evidence of planning, process control and implementation of continuous improvement actions. The result showed that only $42 \%$ met the requirements which makes clear the need for establishing the documentation structure of the QMS.

The documentation structure of the quality management system, based on the requirements of ISO 9001:2015, was done considering the flexibility of its current version. The minimum set of documents were defined for supporting the management of the organization concerning processes, product and services it provides to the interested parties. Documentation include quality manual, mandatory documents, procedures manual and identified and demanded records for achieving international certification. The steps of the Quality Route Method -based on the Deming cycle- were applied. Plan, Do, Check and Act, were used as continuous improvement actions in coachwork manufacturing. This way, problems were solved by using the identified improvement opportunities and a QMS in the manufacturing phase of the product was established.

\section{ACKNOWLEDGEMENT}

This work was financed in part by Universidad Técnica de Ambato (UTA) and Dirección de Investigación y Desarrollo (DIDE) under project PFISEI 26.

\section{REFERENCES}

Chen, C. K., Anchecta, K., Lee, Y. D. and Dahlgaard, J. J. (2016). A stepwise ISO-based TQM implementation approach using ISO 9001: 2015. Management and Production Engineering Review, 7(4), 65-75. https://doi.org/10.1515/mper-2016-0037

Chiarini, A. (2017). Risk-based thinking according to ISO 9001: 2015 standard and the risk sources European manufacturing SMEs intend to manage. The TQM Journal, 29(2), 310-323. https://doi.org/10.1108/TQM-042016-0038

Mihajlović, M. (2018). Methods and Techniques of Quality Process Improvement in the Milk Industry in the Republic of Serbia. Economic Themes, 56(2), 221-237. https://doi.org/10.2478/ethemes-2018-0013

Esgarrancho, S. and Cândido, C. J. (2017). Firm preparation for ISO 9001 certification-the case of the hotel industry in Portugal. Total Quality Management \& Business Excellence, 1-20. https:// doi.org/10.1080/14783363.2017.1404428

Fernández-S. Á., Salazar-L. F., Jurado M., Castellanos E.X., Moreno-P. R. and Buele J. (2019). Electronic System for the Detection of Chicken Eggs Suitable for Incubation through Image Processing, in Rocha Á., Adeli H., Reis L., Costanzo S. (Eds), Advances in Intelligent Systems and Computing, 931. (pp. 208-218). https://doi.org/10.1007/978-3-030-16184-2_21

Franklin, T. O., Tubón-Núñez, E. E., Carrillo, S., Buele, J. and Franklin, S. L. (2019). Quality Management System Based on the ISO 9001: 2015: Study Case of a Coachwork Company. In 2019 14th Iberian Conference on Information Systems and Technologies (CISTI), IEEE, (pp. 1-6). https://doi.org/10.23919/CISTI.2019.8760816

Juanzon, J. B. P. and Muhi, M. M. (2017). Significant factors to motivate small and medium enterprise (SME) construction firms in the Philippines to implement ISO9001: 2008. Procedia Engineering, 171, 354-361. https://doi.org/10.1016/j.proeng.2017.01.344

Ruamchat, K., Thawesaengskulthai, N. and Pongpanich, C. (2017). Development of quality management system under ISO 9001: 2015 and Joint Inspection Group (JIG) for aviation fuelling service. Management and Production Engineering Review, 8(3), 50-59. https:/ / doi.org/10.1515/mper-2017-0028

Sanz-Calcedo, J. G., González, A. G., López, O., Salgado, D. R., Cambero, I., and Herrera, J. M. (2015). Analysis on integrated management of the quality, environment and safety on the industrial projects. Procedia Engineering, 132, 140-145. https://doi.org/10.1016/j.proeng.2015.12.490

Schmeleva, A. N. (2017). Evaluation and Improvement of the Operating Efficiency of Enterprise Quality Management System (QMS): Conceptual bases. Quality - Access to Success, 18(160), 100-107.

Solomon, N. P., Bester, A. and Moll, M. (2017). Diffusion of a quality management system: A case study. South African Journal of Industrial Engineering, 28(2), 149-164. https:/ / doi.org/10.7166/28-2-1762 
Valmohammadi, C. and Kalantari, M. (2017). Using structural equation modelling to test ISO 9000 motivation, depth of ISO implementation and performance of Iranian manufacturing organisations. International Journal of Productivity and Quality Management, 20(3), 405-427. https: / doi.org/10.1504/IJPQM.2017.082675

Velasco, J., Ullauri, R., Pilicita, L., Jácome, B., Saa, P. and Moscoso-Zea, O. (2018). Benefits of Implementing an ISMS According to the ISO 27001 Standard in the Ecuadorian Manufacturing Industry. In 2018 International Conference on Information Systems and Computer Science (INCISCOS), November, IEEE, (pp. 294-300). https://doi.org/10.1109/INCISCOS.2018.00049 